\title{
Uma outra Ameaça Fantasma: a relação entre autor, conteúdos e públicos em The Prequels Strike Back
}

\section{Another Phantom Menace: the relation established by author, contents and audiences in The Prequels Strike Back}

\author{
Pedro Moura* \\ * Centro de Estudos de Comunicação e Sociedade, Universidade do Minho, Portugal
}

Resumo

\begin{abstract}
As prequelas de Star Wars (1999-2005) são, ainda hoje, obras controversas entre os fãs desta narrativa transmediática. O documentário The Prequels Strike Back (2016) procurou compreender a insatisfação de parte destes públicos, mas também a recepção daqueles que, tendo apreciado a segunda trilogia da saga, se viram inseridos numa cultura de antagonismo aos filmes. Neste artigo apresenta-se uma análise do documentário, centrando-se no modo como a recepção das prequelas foi retratada. 0 modelo de cooperação textual de Umberto Eco e os conceitos de cultura de convergência e narrativas transmediáticas de Henry Jenkins foram as principais referências usadas na análise. Concluiu-se que apesar de abordar pertinentemente os diferentes elementos constitutivos da proposta do autor italiano, o documentário ignorou uma dimensão crucial para a compreensão da recepção dos públicos de Star Wars. a natureza transmediática de uma saga que não esteve suspensa entre o final da trilogia original e o lançamento das prequelas.
\end{abstract}

Palavras-chave: Cooperação textual; cultura de convergência; narrativas transmediáticas; Star Wars, Umberto Eco.

Abstract

Star Wars Prequels (1999-2005) are still controversial amidst the fans of this transmedia narrative. The documentary The Prequels Strike Back (2016) sought to understand the frustration of the unhappy part of the audience. It also approached the reception of those who, despite enjoying the second trilogy of the saga, were surrounded by an antagonistic culture towards the prequels. This article develops an analysis of the documentary, focusing on how the prequels' reception was presented. It has Umberto Eco's textual cooperation model and Henry Jenkins' convergence culture and transmedia storytelling concepts as the main analytical references. The article argues that, despite presenting relevant features of Eco's model, the documentary neglects a crucial dimension for understanding the Star Wars audiences' reception: the transmedia nature of a saga that wasn't on hold between the original and the prequel trilogies.

Keywords: Textual cooperation; convergence culture; transmedia storytelling; Star Wars, Umberto Eco.

Submitted: 3rd May 2018

Accepted: 22nd January 2019

\section{Introdução}

Os media desempenham um papel crucial "na produção e circulação de sentido na sociedade" (Jensen, 1995, p. 3). De acordo com Sousa, Zagalo \& Martins (2012), as narrativas que estes difundem assumem uma relevância particular. Como "nem sempre somos capazes de criar as nossas próprias narrativas" (Sousa et al., 2012, p. 168), servimo-nos recorrentemente daquelas que são veiculadas pelos media, inclusivamente nas relações com outros. Transformamo-nos, deste modo, em agentes da sua propagação quando as usamos e recontamos "para além dos limites do enunciado material" (Sousa et al., 2012, p. 168). Tradicionalmente, estas acções aconteciam a uma escala limitada e interpessoal, quando a sociabilidade em 
torno dos media e as práticas de releitura, apropriação e reescrita dos seus conteúdos estavam essencialmente contidas no tempo e em espaços mais imediatos e próximos (Fiske, 1992; Jenkins, 1992; Sousa et al., 2012). A propagação em larga escala de narrativas encontrava-se confinada às indústrias mediáticas. Os meios digitais e online trouxeram a oportunidade para se quebrar este monopólio de produção e circulação de conteúdos, potenciando a extensão da apropriação feita pelos públicos. Consequentemente, a tradicional relação estabelecida entre os produtores institucionais e as audiências dos conteúdos mediáticos também é posta em causa. Conceitos como os de cultura de convergência e de narrativas transmediáticas (Jenkins, 2006; Scolari, 2013b) desenvolveram-se com base nas mudanças expectáveis.

Este artigo analisa a relação entre autor, conteúdos e públicos apresentada pelo documentário de 2016 The Prequels Strike Back, realizado a propósito de uma das mais relevantes narrativas transmediáticas: Star Wars. A análise é feita a partir do modelo de cooperação textual de Umberto Eco (1993), procurando contribuir para a discussão das consequências e dos desafios que a transmedialidade traz à relação estabelecida entre os media - os seus conteúdos e autores - e os públicos. As propostas de Eco são o ponto de partida para a análise de um filme que, citando a sua sinopse ${ }^{1}$, "acompanha a viagem de um fã perplexo" na sua tentativa de "desaprender o que aprendeu" sobre as prequelas de Star Wars. ${ }^{2}$ A trilogia iniciada em 1999 com A Ameaça Fantasma é classificada como "o capítulo mais debatido do maior franchise do cinema", sendo marcada por um forte antagonismo entre George Lucas - o autor ${ }^{3}$ que assumiu as funções de realizador, argumentista e produtor executivo em todos os filmes das prequelas - e parte dos públicos da saga. Antes de avançarmos para a apresentação do modelo de Eco e dos resultados decorrentes da análise ao documentário, importa reflectir sobre o lugar dos públicos nas narrativas transmediáticas.

\section{A relação entre autor, conteúdos e públicos nas narrativas transmediáticas}

Henry Jenkins (2003) definiu as narrativas transmediáticas como as histórias que se desenvolvem com recurso a vários meios, cada um dando contributos diversos para a expansão da narrativa. Os diferentes media seriam usados em articulação, ainda que os seus conteúdos tivessem de ser suficientemente independentes para funcionar como porta de entrada para diferentes públicos. Enquanto forma de apresentar e estruturar histórias e enredos (Cobley, 2001), o storytelling transmediático assenta na criação de mundos (Jenkins, 2006, 2010). De acordo com Scolari (2013b), a maioria das definições tem-se mantido em consonância com a proposta inicial de Jenkins, partilhando a ênfase no desenvolvimento das histórias "através de múltiplos meios e plataformas de comunicação" (Scolari, 2013b, p. 46). Scolari realça, ainda, uma outra dimensão particularmente recorrente nas abordagens às narrativas transmediáticas: o (esperado) papel activo dos públicos na sua expansão. Henry Jenkins também a abordou, enquadrando esta proactividade na sua muito popular proposta sobre a emergência de uma cultura participativa e de convergência (Jenkins, 2006). Se as produtividades enunciativa e textual identificadas por Fiske (1992) - a sociabilidade e a criação e circulação de conteúdos baseados nos textos primários dos media - foram

\footnotetext{
${ }^{1}$ Disponível em https://prequelsstrikeback.com (Consultado em 14 de Fevereiro de 2019).

2 As prequelas referem-se à segunda trilogia de Star Wars, iniciada em 1999. Apesar de terem sido produzidas após a trilogia lançada entre 1977 e 1983, narrativamente centram-se nos eventos que antecederam os três primeiros filmes da saga.

${ }^{3}$ Apesar da natureza colectiva de uma obra como um filme, figuras como o realizador ou o produtor são insistentemente referidas como os seus autores (Coelho, 2017). Isto é ainda mais evidente em Star Wars, onde o estatuto de George Lucas como o criador é particularmente popular (Jenkins, 2003; Lomax, 2017; Pase, Tietzmann \& Gamba, 2017).
} 
consideradas durante muito tempo como distintivas dos fãs, na cultura de convergência, as práticas destes seriam uma janela privilegiada para se pensar a mais ampla transformação da relação entre os media e os seus públicos (Jenkins, 2006).

No campo mediático, a ideia de convergência tem sido frequentemente evocada em associação com a proliferação das tecnologias digitais e online. É um conceito polissémico, usado para descrever aspectos tão distintos como a integração de diferentes indústrias em empresas cada vez maiores ou a pluralidade de linguagens e meios que perfazem as actuais dietas mediáticas (Hesmondalgh, 2007; Couldry, 2011). Jenkins (2006) reconhece esta multiplicidade de sentidos, mas centra-se na dimensão cultural da convergência, mesmo não a definindo explicitamente na obra em causa. Assim, para o autor (Jenkins, 2006, p. 17) a convergência "também ocorre quando as pessoas tomam os media nas suas próprias mãos", quando os públicos, à imagem dos fãs, exigem "o direito a participar" (Jenkins, 2006, p. 24) na produção e circulação de conteúdos. Fazem-no muitas vezes em grupos online, em comunidades de conhecimento, encontrando aí um espaço de recepção colectiva propício para sintetizar a dispersão transmediática das narrativas, mas também onde é possível potenciar o valor da sua voz (colectiva) na relação com as indústrias mediáticas. Estas estão condenadas a escutar os "consumidores reforçados" (Jenkins, 2006, p. 19), até para manterem o seu lucrativo modelo de negócio e a boa vontade que os públicos mostram em relação aos seus conteúdos. Ainda que Jenkins (2006, p. 3) reconheça que "as corporações - e até indivíduos dentro dos media corporativos - ainda exercem um poder maior do que qualquer consumidor individual ou, até, colectivo", parece acreditar simultaneamente que "as tecnologias em rede oferecem aos utilizadores influência suficiente para renegociar as suas relações com as empresas mediáticas" (Van Dijck, 2009, p. 43).

Autores como Couldry (2011) vêem nas propostas de Jenkins um conceito de cultura assente na partilha de um conjunto de valores e sentidos. Deste tipo de leituras tem surgido críticas à cultura de convergência por falta de evidência empírica, por excesso de optimismo e generalização indevida (Van Dijck, 2009; Bird, 2011; Couldry, 2011). Isto porque Jenkins (2006) parte assumidamente de um público muito particular, que mesmo antes do advento das tecnologias digitais e online procurava influenciar o rumo das suas narrativas preferidas: os fãs. Ora, a fandom é tradicionalmente apresentada como "um sentimento conscientemente partilhado de atracção mais ou menos intensa" (McQuail, 2003, p. 413). Portanto, um fã apresenta um nível de comprometimento e esforço - face os conteúdos e com outros fãs (Jenkins, 1992; Grossberg, Wartella \& Whitney, 1998) - necessariamente mais elevado do que o dos demais públicos. Não é garantido que estes, como refere Couldry (2011), estejam dispostos a mimetizá-lo, tal como sugerido pela cultura de convergência. Contudo, se atentarmos na recorrência com que esta é apresentada como uma transformação - em curso, assimétrica e por definir - da relação media/públicos, podemos ler um outro entendimento de cultura mais próximo das suas raízes: enquanto "a tendência de algo" (Williams, 1983, p. 87) onde as contradições e tensões (inclusivamente internas) são parte integrante de um processo (Jenkins, 1992).

Deste modo, apesar das limitações apontadas às propostas de Jenkins, também é certo que nem tudo está igual, que alguns públicos estão, de facto, a conseguir "fazer músculo contra o poder dos produtores dos media para definir os termos do seu envolvimento" (Bird, 2011, p. 506). O caso das prequelas de Star Wars é disso sintomático. Se os fãs desta narrativa transmediática têm historicamente revelado um certo sentido de propriedade (Shefrin, 2004), lutando para preservar o seu entendimento sobre o que a saga é e deve ser, as prequelas despoletaram reacções particularmente adversas, tendo as "as tecnologias em rede", para recuperar a expressão de Van Dijck (2009, p. 43), aumentado o seu alcance e legado para lá dos meios restritos da fandom. Isto traduziu-se, por exemplo, na popularidade online de algumas modificações feitas por fãs, que tomaram em mãos a tarefa de reeditar a $A$ Ameaça Fantasma, aproximando-a do seu 
entendimento de canonicidade (Lyden, 2012). Talvez ainda mais relevante do que estas produções seja a influência e a durabilidade que os discursos dos fãs descontentes com as prequelas atingiram, ao ponto de, segundo The Prequels Strike Back, se constituírem como o discurso dominante no generalizado mundo da Web, onde se desenvolveu uma recepção colectiva das prequelas que abalou a relação entre George Lucas e parte dos públicos de Star Wars.

\section{A relação autor, conteúdos e públicos a partir de Umberto Eco}

A Semiótica e as preocupações com a produção de sentido também têm contribuído para o estudo das narrativas transmediáticas. Carlos A. Scolari (2009, 2013a) destaca-se por uma abordagem semionarratológica, onde a narrativa é tida como "a estrutura básica para a criação de sentido" (Scolari, 2009, p. 591) pela articulação de "textos em diferentes linguagens e media" (Scolari, 2013a, p. 64). Como descrito anteriormente, as narrativas transmediáticas desenvolvem-se com recurso a vários meios, cada um podendo servir de porta de entrada a públicos distintos. Daí que Scolari (2009, p. 592) destaque a importância que "a construção textual dos consumidores" tem no desenvolvimento da estrutura das muito lucrativas narrativas transmediáticas: estas, ao procurarem atingir vários públicos-alvo, desenvolvem-se de forma assimétrica, de modo a chegarem a consumidores com "diferentes capacidades cognitivas" (Scolari, 2009, p. 592). Neste ponto, Scolari socorre-se da concepção de leitor modelo sugerida por Umberto Eco. Contudo, as propostas do autor italiano são mais vastas, evocando elementos particularmente úteis no âmbito deste artigo.

De acordo com Eco (1993, p. 66), a cooperação textual para se chegar à interpretação dos textos realizase a partir de "estratégias discursivas, não entre dois sujeitos individuais". Segundo o autor (Eco, 1993, p. 62), importa distinguir uso de interpretação. O primeiro diz respeito ao "uso livre de um texto tomado como estímulo imaginativo". A segunda "supõe sempre uma dialéctica entre a estratégia do autor e a resposta do leitor modelo" (Eco, 1993, p. 62), estando condicionada pela inscrição cultural mais ou menos partilhada por ambos. Como refere Zara Pinto-Coelho (2010, p. 4), ainda que, num texto, "o número de leituras possa ser infinito, não o é com certeza o seu alcance semântico". Segundo Kress (2001, p. 75), uma qualquer leitura "reconhece que os textos têm manifestações reais (reflectindo a história social da sua criação) que suscitam a tentativa do leitor para Ihes encontrar significados apropriados". Tendo isto em consideração, de acordo com Eco (1993), para existir cooperação textual a relação entre autor e leitores empíricos deve ser feita com base nos textos e no autor e leitor modelo aí latentes.

Um texto é um objecto incompleto, vivendo "da mais-valia de sentido que o destinatário lhe introduz" (Eco, 1993, p. 55). Consequentemente, um texto "está entretecido de espaços em branco, de interstícios a encher" por um leitor (Eco, 1993, p. 55), que o deve actualizar em função das "intenções virtualmente contidas no enunciado" (Eco, 1993, p. 66). Estas intenções não estão confinadas às mais básicas propriedades semânticas do texto, imediatamente disponíveis (Eco, 1979, p. 18); importa também considerar, por exemplo, estratégias como as selecções contextuais e circunstanciais mobilizadas. As primeiras colocam em jogo competências enciclopédicas, evocando implicitamente denotações e conotações culturalmente possíveis e prováveis (Eco, 1991, pp. 94-95, 99) em função da simultaneidade, num texto, de determinados termos pertencentes a um mesmo sistema semiótico. As segundas dizem respeito às referências 
extratextuais, às circunstâncias de enunciação que, quando são linguisticamente codificadas, podem funcionar também como selecções contextuais ${ }^{4}$ (Eco, 1979, p. 19).

O leitor previsto pelo texto é um leitor modelo, um outro hipotético construído pelas estratégias adoptadas pelo autor empírico. Uma das mais relevantes é a escolha de determinadas competências enciclopédicas, isto é, dos conhecimentos e sentidos culturalmente estabelecidos, partilhados em maior ou menor grau (Eco, 1991, p. 88), que o autor empírico espera que sejam reconhecidos e actualizados por esse leitor. Por isso, "gerar um texto significa actuar segundo uma estratégia que inclui as previsões dos movimentos do outro" (Eco, 1993, p. 57). Contudo, o modelo de Eco não se esgota na dicotomia autor empírico/leitor modelo. O leitor empírico, de modo a realizar-se como leitor modelo, tem "o dever de recuperar - com a máxima aproximação possível - os códigos do emissor" (Eco, 1993, p. 66), esboçando um autor modelo como hipótese interpretativa. Isto é possível porque o autor empírico, ao delinear o seu leitor modelo, também se caracterizou "como sujeito do enunciado" (Eco, 1993, p. 65). Ao leitor empírico, no modelo de cooperação textual, não deve interessar as intenções do autor empírico, mas a interpretação culturalmente situada e limitada - e, por isso, distinta do uso livre e aberrante - desse sujeito do enunciado presente no texto. Contudo, as circunstâncias da enunciação podem dificultar a restrição da cooperação às estratégias textuais (Eco, 1993, p. 66). As expectativas do leitor empírico desempenham um papel decisivo na concretização do conteúdo potencial do texto através da cooperação textual:

A configuração do autor modelo depende dos traços textuais, mas põe em jogo o universo do que está por detrás do texto, do destinatário e, provavelmente, também antes do texto e do processo de cooperação (no sentido em que depende da pergunta: «Que pretendemos fazer com este texto?»). (Eco, 1993, pp. 69-70).

Isto é ainda mais evidente em obras assentes na serialidade (e na repetição aí inerente), já que o público espera reencontrar num novo produto de uma qualquer série as estruturas que conhece de textos anteriores (Eco, 1985a, 2016).

\section{Abordagem metodológica}

Como referido no início deste artigo, a análise feita a The Prequels Strike Back centrou-se na relação estabelecida entre autor, conteúdos e públicos, tal como apresentada pelo documentário feito a propósito do antagonismo gerado pelas prequelas de Star Wars. Enquanto análise qualitativa de inspiração hermenêutica, os discursos das diversas fontes a quem foi dada voz são contextualizados pelo todo formado pelo filme, cuja construção narrativa influenciou necessariamente a interpretação feita das partes. Contudo, nos trabalhos hermenêuticos, "o todo textual também deve ser interpretado como parte de totalidades maiores" (Jensen, 2002, p. 21). Daí a preponderância da dimensão transmediática de Star Wars na análise empreendida: enquanto universo ficcional, a saga dos Skywalker vai muito além do cinema. As diferenças

\footnotetext{
${ }^{4}$ A análise que Eco fez do James Bond de Ian Fleming, publicada originalmente em meados dos anos 1970, mostra como as circunstâncias de enunciação podem ser transformadas em selecções contextuais. Fleming, um "engenheiro da narrativa de consumo" que criou após a Segunda Guerra Mundial e em plena Guerra Fria (Eco, 2016, p. 166), evocou, pela redacção de personagens estereotipadas e de enredos previsíveis, dicotomias históricas e o ambiente geopolítico vivido por ele e pelos seus leitores contemporâneos. Fleming solicitou "a nossa capacidade de identificação" (Eco, 2016, p. 173) ao apresentar um discurso implicitamente marcado pelo "conhecimento pressuposto [que] faz parte do common ground sociocultural" (Van Dijk, 2005, p. 54).
} 
entre as extensões das narrativas transmediáticas - com affordances e modos semióticos variados influenciam necessariamente a criação de sentido (Kress, 2001).

Assim, os argumentos das fontes do documentário e da narrativa formada pelo filme foram analisados à luz do modelo de cooperação textual de Umberto Eco, procurando dar resposta às seguintes questões:

- Como é que o autor empírico, George Lucas, é apresentado e de que modo difere do autor modelo esperado pelos leitores empíricos tratados pelo documentário?

- Quais os leitores modelo de George Lucas quando este criou as prequelas, tal como retratados pelo documentário, e porque é que não coincidem com parte dos fãs da trilogia original?

- Como é que a dimensão transmediática de Star Wars é apresentada no documentário? Ajuda a explicar a divergência entre Lucas e parte dos fãs de Star Wars? Teve, de acordo com o que é veiculado pelo documentário, influência na construção das expectativas dos públicos, que, entre 1983 e 1999 só contactaram com novos produções de Star Wars em meios que não a do cinema?

Em suma, este artigo procurou "interpretar a interpretação de outros" (Jensen, 2002, p. 22), seja a das fontes do documentário, seja a dos autores de The Prequels Strike Back. O documentário, enquanto texto, é encarado como a "manifestação semiótica de processos sociais materiais" (Iedema, 2001, p. 187).

\section{Uma breve descrição de The Prequels Strike Back}

Como é visível no site oficial ${ }^{5}$ do documentário em estudo, The Prequels Strike Back é um pequeno filme independente, produzido pelo estúdio texano Ministery of Films e financiado com recurso a crowdfunding. De acordo com um vídeo publicado pela Ministery of Films no YouTube ${ }^{6}$, o orçamento disponível para a realização do documentário foi de pouco mais de 12.700 dólares norte-americanos. Há dois nomes que se destacam na atribuição que o site faz relativamente à autoria da obra: Bradley Weatherholt, produtor, argumentista e realizador, e Kyle Brodeur, produtor e editor. O filme de 2016 desenrola-se durante aproximadamente uma hora e 20 minutos. Centra-se, como descrito anteriormente, na viagem de um fã de Star Wars, que parte para o terreno com a seguinte interrogação: "e se quem foi ao cinema tiver examinado os filmes [as prequelas] somente a partir de um ponto de vista?". Esse fã, cujo nome e idade (24 anos) ficamos a conhecer somente no início do segundo terço do filme, é Bradley Weatherholt. Este é também o narrador.

O documentário, para além de um prólogo e de um epílogo, está divido em sete partes, tantas quanto os filmes de Star Wars estreados até 2016. Os cinco primeiros capítulos são os mais relevantes face aos propósitos deste artigo, visto que se dedicam quase em exclusivo ao antagonismo dos fãs insatisfeitos face a George Lucas em resultado das prequelas. O tom é quase invariavelmente de defesa do cineasta norteamericano: as quatro vozes notoriamente críticas que contabilizámos são sucessivamente contrabalançadas por várias outras que atenuam as razões da sua insatisfação. Para além disto, todos estes fãs descontentes acabaram por ter pelo menos uma aparição na narrativa criada por The Prequels Strike Back a elogiar um qualquer aspecto das prequelas ou a relativizar o seu descontentamento. Esta benevolência generalizada

\footnotetext{
${ }^{5}$ https://prequelsstrikeback.com/about (Consultado em 14 de Fevereiro de 2019).

${ }^{6}$ https://www.youtube.com/watch?v=Rdli09UfGFU (Consultado em 14 de Fevereiro de 2019).
} 
talvez explique o facto de não termos encontrado diferenças significativas na escala de planos usada. Ao contrário do que, por exemplo, Iedema (2001) constatou na análise de um documentário sobre o quotidiano de um hospital australiano, onde planos mais próximos indiciavam uma maior simpatia por profissionais de saúde e pacientes em desfavor dos gestores hospitalares, em The Prequels Strike Back as diversas fontes são enquadradas quase invariavelmente entre planos médio e próximo. Muitas das pessoas entrevistadas foram filmadas em cenários povoados com elementos relacionados com Star Wars, tais como figuras de acção ou, até, extensões transmediáticas da narrativa (livros, sobretudo).

No prólogo, o narrador descreve o seu percurso enquanto fã de Star Wars. Em criança, "amava" todos os filmes da saga, incluindo as prequelas. Para esse jovem, "Star Wars era Star Wars". Contudo, esta visão holística da saga mudou assim que cresceu, em muito devido ao contacto com outros fãs através da internet. "Mais velho e mais exposto à internet, aprendi que a minha visão de Star Wars estava errada", ouvimos Bradley Weatherholt a dizer em offenquanto o vemos em frente a um computador, a navegar em algo que se assemelha a um fórum online. Segundo o narrador, os seis filmes de George Lucas já não constituíam uma saga, antes formavam duas trilogias. Uma boa e uma má. Como consequência desta participação em comunidades de conhecimento onde se jogava uma recepção grupal das prequelas, o narrador confessa ter passado a adolescência a "abandonar os filmes de que gostava enquanto criança". Quando chega à idade adulta decide questionar este percurso, desaprendendo o que aprendeu sobre as prequelas de Star Wars. Vemo-lo, no início do primeiro capítulo, a iniciar uma viagem para entrar em contacto com várias pessoas, com diferentes proveniências, idades e especializações. Ao longo dos sete capítulos são apresentadas 31 fontes.

As fontes a quem The Prequels Strike Back dá voz são-nos introduzidas visualmente como tendo perfis variados, que podem, ainda assim, ser agregados em sete categorias em função da forma como foram apresentadas pelo próprio documentário através da identificação visual onde constavam nome e profissão ou estatuto (Tabela 1). Todas expressam algum grau de apreço por Star Wars - como um todo ou somente pela primeira trilogia. Apesar da distinção que é possível fazer entre as duas categorias mais populosas, as 17 fontes aí constantes também podiam ser agrupadas sob a designação do segundo grupo, caso o critério fosse o discurso que veicularam e não a apresentação feita pelo documentário. Ou seja, ainda que nove pessoas nos sejam visualmente introduzidas como criadores de conteúdos (alguns inspirados em Star Wars), estas falam enquanto fãs da saga.

Tabela 1: Perfil das fontes ouvidas no documentário

\begin{tabular}{|l|c|}
\hline Perfis (tais como visualmente apresentados) & Número de fontes \\
\hline Criadores de conteúdos (podcasters, escritores, etc.) & 9 \\
\hline Fãs de Star Wars & 5 \\
\hline Investigadores sobre cinema (académicos, film theorist) & 4 \\
\hline Profissionais de cinema & 2 \\
\hline Profissionais de cinema que colaboraram com as prequelas & 2 \\
\hline Críticos de cinema & 1 \\
\hline Jornalistas especializado em música & $\mathbf{3 1}$ \\
\hline \multicolumn{2}{|c|}{ Total } \\
\hline
\end{tabular}

Apesar da variedade de vozes presentes no documentário, há nove fontes que se destacam pela relevância que têm na construção narrativa. Sabendo-se que o filme é sobre a viagem do narrador, essas nove são 
aquelas com quem o vemos a interagir ou o ouvimos dizer que foi ao seu encontro. Funcionam como arquétipos das críticas e da defesa de George Lucas, com as últimas a estarem em clara maioria: as vozes críticas são três e, como referido, não o são em absoluto. As restantes 22 fontes surgem sem que seja visível ou audível o seu contacto com o fã em viagem, ainda que reforcem os argumentos tipificados pelas nove que podemos adjectivar como privilegiadas. Destas, seis são particularmente relevantes face aos propósitos deste trabalho ${ }^{7}$. Os seus contributos para se pensar a relação estabelecida entre autor, conteúdos e públicos sustentada por The Prequels Strike Back encontram-se detalhados no ponto seguinte.

\section{Um certo ponto de vista: análise de The Prequels Strike Back}

O documentário, no primeiro capítulo, começa por apresentar George Lucas. Este é descrito "como um dos deuses das mitologias em que se inspirou", capaz de tirar e de dar. É igualmente alguém que divide opiniões - umas são negativas, outras favoráveis. Consequentemente, o discurso sobre o descontentamento dos fãs em relação a George Lucas não nos é apresentado como sendo unânime: somente uma parte dos mais comprometidos apreciadores de Star Wars se sentiu atraiçoada pela segunda trilogia, de acordo com The Prequels Strike Back. Uma das justificações mais salientes para este descontentamento está relacionada com a idade dos fãs: os mais velhos não gostaram, ao contrário dos mais novos. O desenvolvimento deste argumento centra-se na discrepância entre os leitores modelo previstos pelas estratégias textuais adoptadas por George Lucas e as expectativas dos fãs mais velhos de Star Wars, os leitores empíricos que, por sua vez, eram crianças aquando da estreia da trilogia original. Ou seja, segundo The Prequels Strike Back e a maioria das suas fontes, George Lucas construiu um filme para as crianças da década de 90 e não para os adultos que o tinham sido há vinte anos, aquando do lançamento dos três primeiros filmes da saga, materializando estas intenções em personagens propositadamente tontas que, por isso, suscitavam o riso dos mais novos.

Esta explicação é recorrentemente evocada ao longo do documentário, constituindo-se como uma das mais significativas justificações avançadas para a relação tensa entre George Lucas e parte dos fãs de Star Wars. A primeira das nove fontes com quem vemos o narrador a interagir consubstancia-se como arquétipo deste argumento. O encontro do narrador com Randy Davies, que nos é apresentado como sendo um coleccionador de merchandising relacionado com Star Wars, começa com uma visita à sua colecção, que inclui inúmeros produtos da saga: da trilogia original, do primeiro filme produzido pela Disney e, também, das por ele mal-amadas prequelas. Estas, de acordo com Randy Davies, para além de contarem "muitas coisas que não precisavam de ser contadas", são particularmente deficitárias no que às personagens e às performances dos actores diz respeito. O romance entre duas das personagens principais é apontado como exemplo: "tu vê-lo agora enquanto adulto e quase que te encolhes". Este argumento, onde a idade assume um peso considerável, até por causa da implicatura suscitada pela referência ao "agora enquanto adulto"8, é prontamente relativizado quer pelas restantes fontes ouvidas, quer pela narrativa do documentário. Sobretudo por não ser algo de novo.

\footnotetext{
${ }^{7}$ As restantes três dedicam-se a analisar a dimensão mitológica de Star Wars, desviando-se da centralidade que a relação entre autor e públicos assume no âmbito do artigo.

${ }^{8}$ Esta formulação leva-nos necessariamente às seguintes questões: e enquanto criança? Também provocou a mesma repulsa? Nenhuma destas interrogações é explicitamente respondida. Ainda que não nos seja revelada a idade de Randy Davies, este não aparenta ser muito mais velho do que o narrador: ou seja, seria uma criança ou um adolescente em 1999, ano da estreia da primeira prequela.
} 
A trilogia original é-nos apresentada como também tendo tido más críticas no momento do seu lançamento. Críticas de adultos, que viram o primeiro episódio da saga como um "filme tonto para crianças", com personagens irritantes e performances fracas. $\mathrm{O}$ que as distingue das prequelas é o facto de estas terem sido lançadas quando mais adultos conseguiam fazer ouvir a sua voz em espaços online. Os meios de discussão na Internet são, por regra, caracterizados negativamente ao longo do documentário: são tidos como espaços onde a crítica fácil e anónima prolifera. Uma das outras fontes privilegiadas pelo documentário é Kevin Smith, realizador de cinema e um muito conhecido fã de Star Wars. Este resume a argumentação em torno da idade: "vai-se assistir a uma geração de miúdos que cresceram a ver as prequelas e que não se sentiram do mesmo modo que nós. Éramos apenas a voz mais ruidosa na sala". Mesmo que essa sala não fosse a de cinema, mas os espaços online.

Contudo, em The Prequels Strike Back nem só a idade dos leitores modelo previstos pelas prequelas é apontada como razão para o afastamento de George Lucas em relação a parte dos fãs. As enciclopédias de ambos, para recuperar um conceito de Eco (1993), não coincidiam no que diz respeito ao storytelling. Como consequência, a cooperação textual entre autor e leitores empíricos ficou comprometida. George Lucas é recorrentemente caracterizado como um cineasta focado na construção de narrativas audiovisuais, contrastando com uma audiência habituada a analisar um filme pelo seu enredo e pelos seus diálogos. Três das nove fontes privilegiadas dedicam-se ao desenvolvimento deste argumento. Destas, Mike Klimo, um film theorist conhecido por ter apontado a natureza quiasmática da narrativa de Star Wars, é aquela a quem é dada voz mais frequentemente ${ }^{9}$. De acordo com Klimo, o estilo narrativo de George Lucas, moldado quer pelo cinema mudo dos anos 30 quer pelo cinema experimental norte-americano da década de 60, não foi reconhecido e apreciado pela maioria dos públicos que assistiu às prequelas. A forma como Lucas escreve e realiza foi-nos apresentada recorrentemente ao longo do documentário como estando fora de moda. Para além disto, a cinefilia do autor também não foi identificada pelos públicos: esta limitação na percepção da intertextualidade cinematográfica das prequelas condicionou a sua fruição (Eco, 1985b), neste caso pelos públicos mais velhos. Exemplificando, o que para muitos não passou de um conjunto de comportamentos bizarros e irritantes de personagens como Jar Jar Binks, classificada pelo narrador como a mais odiada da história do cinema, para Lucas seria uma forma de homenagear as comédias mudas protagonizadas por Buster Keaton. Para além disto, a narrativa seria pensada em termos eminentemente audiovisuais, como se se pudesse dispensar a palavra em favor da edição, da sucessão de imagens e da banda sonora enquanto "elementos de movimento", citando Joshua Sikora, um dos académicos presentes em The Prequels Strike Back. A narrativa do documentário também favorece esta interpretação: no seu Epílogo temos o narrador a concluir que "o que fez de Star Wars fantástico não foram os diálogos, foi a imagem de um Star Destroyer, o som de um lightsaber. Foi aquele sentimento de infância". Mais, o narrador avança uma outra hipótese, a da maior resiliência do audiovisual em relação aos estilos de representação e de redacção de diálogos, pretensamente menos duradouros quando comparados com a "intemporalidade da imagem e do som". Também por aqui se percebe que The Prequels Strike Back é construído enquanto defesa da linguagem de George Lucas, uma linguagem marcadamente cinéfila e inibidora de cooperação textual por não ser partilhada pelos fãs descontentes.

No documentário foi apresentado ainda um outro elemento intrinsecamente relacionado com o modelo de cooperação textual de Eco (1993): o impacto das expectativas prévias dos públicos. Como vimos, para Eco

\footnotetext{
${ }^{9}$ As restantes são Anne Lancashire, investigadora da Universidade de Toronto, que defende as inovações trazidas pela unicidade narrativa dos seis filmes, e Doug Adams, jornalista de música que salienta o papel da banda sonora composta por John Williams, sobretudo pelos leitmotiv usados, na construção de uma narrativa eminentemente audiovisual.
} 
o que está antes da cooperação textual também a influencia. E em obras marcadas pela serialidade, a procura da repetição faz parte das expectativas dos públicos (Eco, 1985a, 2016). É precisamente a este propósito que nos são apresentados Bryan Connely e Fon Davis, duas outras fontes com quem vemos o narrador a interagir. O primeiro é um fã insatisfeito com as prequelas, ainda que por motivos distintos dos que foram tratados anteriormente. A razão para o descontentamento é fundamentalmente visual: as prequelas não se pareciam com a trilogia original. O uso de efeitos computorizados, visualmente diferentes de técnicas artesanais e com potencialidades que facilitaram a gravação de outro tipo de planos, é apontado como a causa da deriva estética. $O$ documentário insere esta queixa num todo mais vasto: a má reputação granjeada pelos efeitos computorizados em finais do século XX e inícios do século XXI, sendo esta confirmada por profissionais da área, que reconhecem alguns maus usos dos efeitos gerados por computadores. Entre eles encontra-se Fon Davis, que trabalhou nas prequelas. Contudo, esta fonte serve um outro propósito para além da confirmação da reputação citada. Fon Davis é narrativamente usado para desmistificar o abandono de técnicas não digitais na trilogia iniciada em 1999: dele ouvimos que, ao contrário do que já se tornou senso comum e que contribuiu, de acordo com o documentário, para a má reputação das prequelas, os filmes tidos como exclusivamente digitais usaram, afinal, mais efeitos artesanais do que qualquer uma das obras da trilogia original.

O impacto das expectativas dos fãs na fruição das prequelas não foi abordado somente pelo desejo de ver algo esteticamente semelhante. As consequências da espera também se encontram contemplados no documentário. Kevin Smith deu voz a este argumento: "muitas pessoas tinham um conjunto de expectativas sobre o que é que um filme de Star Wars devia ser" e estas acabaram por não ser cumpridas. Uma outra fonte, Christopher Moonlight, desenvolveu um pouco mais esta ideia, associando-a ao lapso de tempo que intermediou o último filme da trilogia original e o primeiro das prequelas: "as pessoas trouxeram 25 anos de expectativas dos antigos para os novos filmes". Contudo, nos 17 anos que passaram entre lançamentos cinematográficos, Star Wars não foi somente revisitado pelos fãs a partir dos filmes. Várias fontes do documentário referem o impacto que as entrevistas que George Lucas foi dando durante este intervalo tiveram nas antevisões sobre qual seria o futuro da saga. Apesar de ser claramente relevante, este é um argumento insuficiente para se problematizar a criação de expectativas. O facto de Star Wars ser uma narrativa transmediática em quase permanente expansão parece-nos ser uma hipótese indispensável para se pensar as expectativas dos fãs. Como refere Jenkins:

Apesar da distância temporal entre as estreias de $O$ Regresso do Jedi (1983) e $A$ Ameaça Fantasma (1999), a Lucasfilm [produtora de Star Wars] continuou a gerar lucros a partir do seu franchise através da produção de livros e bandas desenhadas originais, da distribuição de cassetes de vídeo e de áudio, da continuada promoção de brinquedos e produtos de Star Wars, e da manutenção de um elaborado aparelho de comunicação, incluindo uma newsletter mensal para fãs de Star Wars. (Jenkins, 2006, p. 146).

Contudo, a transmedialidade da saga não é praticamente abordada ao longo do documentário, encontrandose quase ausente da narrativa construída em The Prequels Strike Back. Na maioria das vezes, existe somente enquanto adereço cénico: são várias as fontes que falam ladeadas pelas extensões de Star Wars, como descrito na caracterização do documentário. Os únicos resquícios da transmedialidade (da sua inserção na cultura de convergência) são as comunidades de fãs e o documentário apresenta-as somente como um 
espaço de crítica às prequelas, nomeadamente em ambiente online. Contudo, estas são mais do que lugares reactivos. Ou seja, enquanto comunidades são espaços privilegiados para a criação comunal de expectativas, de meta-textos em relação aos quais os conteúdos serão interpretados ou reinterpretados (Jenkins, 1992). Não são, por isso, somente espaços de reacção à chegada de novos conteúdos, antes lugares de proactividade na definição e redefinição - pelas práticas de releitura e reescrita aí existentes - de um rumo (tido como) certo pela comunidade. No restante, tudo e todos confluem em The Prequels Strike Back para o cinema, como se fosse o único meio e linguagem geradores de sentido. Contudo, a natureza transmediática de Star Wars terá certamente tido impacto na criação das expectativas dos fãs. Voltando a Jenkins:

Quando Star Wars avançou para suportes escritos, os seus livros expandiram a cronologia para nos mostrar eventos que não estavam nos filmes ou para reformular histórias em torno de personagens secundárias [...]. Quando Star Wars avançou para os jogos, estes não se limitaram a recriar os eventos dos filmes; mostraram-nos como seria a vida de um aprendiz de Jedi ou de um caçador de prémios. (Jenkins, 2003)

Estes meios tinham linguagens e estéticas necessariamente diferentes: por causa das capacidades e das especificidades técnicas de cada um, pelo grau de investimento feito em cada novo produto e, claro, como consequência da participação de diferentes autores, com enciclopédias distintas da de George Lucas. Para além disto, o papel dos utilizadores não é igual em todos os media: não se percorre a história de um filme do mesmo modo que se participa no desenrolar da narrativa de um videojogo. Os fãs que cresceram a revisitar a trilogia original fizeram-no acompanhados de outros elementos - canónicos ou não, com origem na Lucasfilm ou na fandom relativa a Star Wars - que, por serem intrinsecamente diferentes, influenciaram as expectativas sobre o que é (e o que devia ser) Star Wars.

A centralidade que George Lucas desempenhava na organização da saga também tem aqui um papel potencialmente decisivo. Esta, até à sua aquisição pela Disney em 2012, encontrava-se dividida em cânone e universo expandido - ou seja, entre histórias oficiais e não oficiais, mesmo quando as últimas eram publicadas com a chancela da Lucasfilm. Contudo, mesmo dentro do cânone, o cinema assumia um lugar privilegiado, acima das demais histórias oficiais, podendo, até, contradizê-las. Isto mesmo foi reconhecido por George Lucas em entrevista:

Quando disse que outros podiam fazer as suas próprias histórias de Star Wars, decidimos que, tal como Star Trek, teríamos dois universos: o meu universo e o universo dos outros. Eles tentam fazer com que o seu universo seja tão consistente quanto possível com o meu, mas obviamente que se entusiasmam e seguem por outras direcções. (Spelling, 2005, p. 48)

No final do quinto capítulo, The Prequels Strike Back evoca Roland Barthes e o seu ensaio A Morte do Autor, sustentando que "o sentido de um trabalho só existe quando interpretado". Apesar da relevância do trabalho de Barthes para se abandonar a sacralização das intenções alegadamente transparentes dos autores e da consonância do seu entendimento de leitor - não uma pessoa concreta, mas "aquele que agrega num único campo todos os traços pelos quais o texto escrito é constituído" (Barthes, 1977, p. 148) - com o leitor modelo de Eco, parece-nos fundamental não declarar a morte do autor. A constituição de um autor modelo, 
como vimos a propósito do documentário, só artificialmente se encontra confinada aos textos. Sobretudo em Star Wars, como nos deu conta o fã descontente Randy Davies: "falo de George Lucas como se o conhecesse a nível pessoal. Mas quase que o conheço. Porque cresci a ouvi-lo". A ele, nas entrevistas a que Davies se refere, e à saga que tutelou, mesmo quando as suas variadas extensões não seguiam os caminhos traçados pelo cinema de George Lucas.

\section{Notas finais}

Considerando a análise apresentada, parece-nos justo afirmar a pertinência das propostas de Umberto Eco para se perceber a tensão no seio de Star Wars, mesmo quando estudada a partir de um objecto assumidamente posicionado ao lado de George Lucas e, consequentemente, em oposição aos fãs descontentes que ainda hoje existem. Contudo, nem todas as partes das propostas de Eco relativas à cooperação textual se aplicam pacificamente ao estudo de uma narrativa transmediática como Star Wars. Se, tal como avançado por Scolari (2009, p. 591), a "construção textual dos consumidores" é uma prática recorrente numa indústria desejosa de chegar a públicos distintos, a pluralidade de extensões de uma narrativa constantemente renovada por novos conteúdos problematiza a restrição do autor modelo às estratégias textuais contidas num único texto. Neste mesmo sentido, a ideia de interpretação tal como proposta por Eco também nos parece problemática. Para o autor, a interpretação encontra-se intrinsecamente associada ao texto, ao contrário do uso. Contudo, face à multiplicidade de textos que contribuem para a criação (nem sempre coerente) das histórias das narrativas transmediáticas, até que ponto podemos falar de uso quando uma leitura, mesmo contrariando as estratégias textuais de uma extensão em concreto, permanece coerente com outras apresentadas em conteúdos distintos da mesma narrativa transmediática?

Assim, partindo da análise de The Prequels Strike Back, importa destacar alguns dos desafios que a transmedialidade de muitas das mais populares narrativas da actualidade traz às investigações sobre os públicos. No estudo da recepção das narrativas transmediáticas (mesmo quando a investigação se foca nos públicos de uma única modalidade, como as prequelas de Star Wars, por exemplo), a natureza transmediática da narrativa não pode ser ignorada, já que constitui, em potência e à imagem dos géneros (Esquenazi, 2006), um verdadeiro contexto de recepção. Como exemplificou Jean-Pierre Esquenazi, um fã de Westerns pode ficar decepcionado se não encontrar aí índios e cowboys. Estes fazem parte "do conhecimento que permite ao público preparar o seu comportamento ao nível da recepção" (Esquenazi, 2006, p. 18). Como já referido a propósito de Eco (1985a, 2016), o público de determinados géneros espera encontrar o que já conhece. No caso das narrativas transmediáticas, a sua regular expansão no tempo e no espaço - com os sucessivos lançamentos de novas extensões, consumos recorrentes de reposições e de obras derivadas ou, claro, a própria persistência da produtividade enunciativa e textual (Fiske, 1992) dos públicos - tornam o processo de recepção em torno de uma só obra numa (quase) impossibilidade. A transmedialidade, tal como os géneros, funciona como "um instrumento de socialização" (Esquenazi, 2006, p. 18) das diferentes extensões da narrativa. Dito isto, importa também problematizar a intertextualidade em torno das narrativas transmediáticas. Como apresentado na análise feita a The Prequels Strike Back, não foram somente as diversas manifestações da história (canónicas ou não) que condicionaram a recepção de Star Wars. Textos fora do eixo corporativo (Hardy, 2011), como notícias, entrevistas ou, até, as conversas 
e as criações dos fãs, podem também ter contribuído de modo relevante para a construção de sentido e de expectativas dos públicos insatisfeitos com as prequelas.

\section{Apoios}

Este trabalho foi realizado no âmbito do projecto de doutoramento em Ciências da Comunicação, na Universidade do Minho, financiado pela Fundação para a Ciência e a Tecnologia através da bolsa com a referência SFRH/BD/124039/2016.

\section{Referências bibliográficas}

Barthes, R. (1977). The Death of the Author. In R. Barthes, Image Music Text (pp. 142-148). London: Fontana Press.

Bird, S. E. (2011). Are we all prosumers now? Convergence and media audience practices. Cultural Studies, 25 (4-5), 502-516. doi: 10.1080/09502386.2011.600532.

Cobley, P. (2001). Narrative. London: Routledge.

Coelho, I. B. R. (2017). Quando a autoria a solo não é suficiente. In S. Pereira \& M. Pinto (Eds.), Literacia, Media e Cidadania - Livro de Atas do $4 .{ }^{\circ}$ Congresso (pp. 194-205). Braga: CECS. Retirado de http://www.lasics.uminho.pt/ojs/index.php/cecs ebooks/article/view/2675 (Consultado em $14 \mathrm{de}$ Fevereiro de 2019).

Couldry, N. (2011). More Sociology, More Culture, More Politics. Or, a modest proposal for 'convergence' studies. Cultural Studies, 2 (4-5), 487-501. doi: 10.1080/09502386.2011.600528.

Eco, U. (1979). The Role of the Reader - Explorations in the Semiotics of Texts. Bloomington: Indiana University Press.

Eco, U. (1985a). Innovation \& repetition: between modern \& postmodern aesthetics. Dædalus, 114 (4), 161-184.

Eco, U. (1985b). "Casablanca": Cult Movies and Intertextual Collage. SubStance, 14 (2), 3-12.

Eco, U. (1991). Tratado Geral de Semiótica. São Paulo: Editora Perspectiva.

Eco, U. (1993). Leitura do texto literário - Lector in fabula. Lisboa: Editorial Presença.

Eco, U. (2016). O Super-Homem das Massas. Lisboa. Relógio D'Água.

Esquenazi, J-P. (2006). Sociologia dos Públicos. Porto: Porto Editora.

Fiske, J. (1992). The Cultural Economy of Fandom. In L. A. Lewis (Ed.), The Adoring Audience - Fan culture and popular media (pp. 30-49). London: Routledge.

Grossberg, L., Wartella, E. \& Whitney, C. (1998). MediaMaking: Mass Media in Popular Culture. Thousand Oaks: SAGE Publications.

Hardy, J. (2011). Mapping commercial intertextuality: HBO's True Blood. Convergence, 17(1), 7-17. doi: $10.1177 / 1354856510383359$.

Hesmondalgh, D. (2007). The Cultural Industries - 2nd Edition. London: SAGE Publications.

Iedema, R. (2001). Analysing film and television: a social semiotic account of Hospital: An Unhealthy Business. In T. van Leeuwn \& C. Jewitt (Eds.), Handbook of Visual Analysis (pp. 183-204). London: SAGE Publications. 
Jenkins, H. (1992). Textual Poachers - Television fans and participatory culture. New Yok: Routledge.

Jenkins, H. (2003, 15 de janeiro). Transmedia Storytelling: Moving characters from books to films to video games can make them stronger. MIT Technology Review. Retirado de https://www.technologyreview.com/s/401760/transmedia-storytelling (Consultado em 14 de Fevereiro de 2019).

Jenkins, H. (2006). Convergence Culture - Where old and new media collide. New York: New York University Press.

Jenkins, H. (2010). Transmedia Storytelling and Entertainment: An annotated syllabus. Continuum: Journal of Media \& Cultural Studies, 24(6), 943-958. doi: 10.1080/10304312.2010.510599.

Jensen, K. B. (1995). The Social Semiotics of Mass Communication. London: SAGE Publications.

Jensen, K. B. (2002). The humanities in media and communication research. In K. B. Jensen (Ed.), $A$ Handbook of Media and Communication Research (pp. 15-39). London: Routledge.

Kress, G. (2001). Sociolinguistics and Social Semiotics. In P. Cobley (Ed.), The Routledge Companion to Semiotics and Linguistics (pp. 66-82). London: Routledge.

Lomax, T. (2017). "Thank the Maker!". George Lucas, Lucasfilm, and the Legends of Transtextual Authorship across the Star Wars Franchise. In S. Guynes \& D. Hassler-Forest (Eds), Star Wars and the History of Transmedia Storytelling (pp. 35-48). Amsterdam: Amsterdam University Press.

Lyden, J. C. (2012). Whose Film Is It, Anyway? Canonicity and Authority in Star Wars Fandom. Journal of the American Academy of Religion, 80 (3), 775-786. doi: 10.1093/jaarel/lfs037.

McQuail, D. (2003). Teoria da Comunicação de Massas. Lisboa: Fundação Calouste Gulbenkian.

Pase, A. F., Tietzmann, R. \& Gamba, J. S. (2017). George Lucas: pós-produção como um espaço de teoria e prática. In M. Penafria, E. T. Baggio, A. R. Graça \& D. C. Araujo (Eds.), Revisitar a teoria do cinema: Teoria dos cineastas - Vol. 3 (pp. 41-57). Covilhã: LabCom.IFP. [eBook]. Retirado de http://www.labcom-ifp.ubi.pt/book/304 (Consultado em 14 de Fevereiro de 2019).

Pinto-Coelho, Z. (2010, fevereiro). Porquê a Semiótica? Comunicação apresentada no workshop Espaços da Semiótica, 1.0 Encontro do Grupo de Trabalho de Semiótica - Sopcom, Lisboa. Retirado de http://hdl.handle.net/1822/29722 (Consultado em 14 de Fevereiro de 2019).

Shefrin, E. (2004). Lord of the Rings, Star Wars, and participatory fandom: mapping new congruencies between the internet and media entertainment culture. Critical Studies in Media Communication, 21(3), 261-281. doi: 10.1080/0739318042000212729.

Scolari, C. A. (2009). Transmedia Storytelling: Implicit Consumers, Narrative Worlds, and Branding in Contemporary Media Production. International Journal of Communication, 3, 586-606.

Scolari, C. A. (2013a). Lostology: Transmedia storytelling and expansion/compression strategies. Semiotica, 195, 45-68. doi: 10.1515/sem-2013-0038.

Scolari, C. A. (2013b). Narrativas transmedia: cuando todos los medios cuentan. Barcelona: Deusto.

Sousa, M. N., Zagalo, N. \& Martins, M. (2012). "Eu Também Posso Propagar Histórias". A Adaptação e as Narrativas Transmediáticas na Era da Participação. Comunicação e Sociedade, 22, 167-183. doi: 10.17231/comsoc.22(2012).1280.

Spelling, I. (2005, agosto). New Hopes. Starlog, 337, 46-52.

Van Dijk, T. A. (2005). Discurso, Notícia e Ideologia - Estudos na Análise Critica do Discurso. Porto: Campo das Letras.

Van Dijck, J. (2009). Users like you? Theorizing agency in user-generated content. Media, Culture \& Society, 31 (1), 41-58. doi: 10.1177/0163443708098245. 
Williams, R. (1983). Keywords. A vocabulary of culture and society. New York: Oxford University Press. 